\title{
Caffeine Reduces Apnea Frequency and Enhances Ventilatory Long-Term Facilitation in Rat Pups Raised in Chronic Intermittent Hypoxia
}

\author{
CÉCILE A. JULIEN, VINCENT JOSEPH, AND AIDA BAIRAM \\ Département de Pédiatrie, Hôpital Saint-François d'Assise, Université Laval, Québec, Canada G1L3L5
}

\begin{abstract}
The mechanisms underlying the therapeutic function of caffeine on apneas in preterm neonates are not well determined. To better understand these effects, we exposed rat pups from postnatal $\mathrm{d}$ $3-12$ to chronic intermittent hypoxia $\left(5 \% \mathrm{O}_{2} / 100 \mathrm{~s}\right.$ every $10 \mathrm{~min} ; 6$ cycles/h followed by $1 \mathrm{~h}$ at $\left.21 \% \mathrm{O}_{2}, 24 \mathrm{~h} / \mathrm{d}\right)$, a model mimicking hypoxemic exposure in apneic neonates. Then, using whole-body plethysmography, we evaluated minute ventilation, apnea frequency, and duration after i.p injection of caffeine citrate $(20 \mathrm{mg} / \mathrm{kg})$ or saline under normoxia and in response to either sustained $\left(\mathrm{FiO}_{2} 12 \%, 20\right.$ min) or brief $\left(\mathrm{FiO}_{2} 5 \%, 60 \mathrm{~s}\right.$, total 10 episodes of 8 min each) hypoxia. These tests were used to assess peripheral and central components of hypoxic response. The latter also assessed the ventilatory long-term facilitation during recovery $(2 \mathrm{~h})$. Caffeine injection increased minute ventilation under baseline and during recovery. This effect was correlated with a decrease in apnea frequency (not duration). On the contrary, caffeine did not change the ventilatory response to sustained or brief hypoxic exposure. These results suggest that the effects of caffeine on apnea depend on increased central normoxic respiratory drive and enhancement of ventilatory long-term facilitation rather than on higher hypoxic ventilatory response. (Pediatr Res 68: 105-111, 2010)
\end{abstract}

$\mathrm{C}$ affeine, an antagonist of adenosine receptors and a potent central nervous system stimulant, has been described as an interesting pharmacological agent to reduce apneas in neonates some 40 y ago (1). Caffeine now is the current therapy to treat apneas in preterm neonates (2). To better understand this pharmacological property, several studies have described the effects of caffeine on the respiratory control system. These studies have shown that caffeine increases ventilatory drive $(1,3)$, acts directly on the respiratory control system in the brainstem (4), and improves the sensitivity and/or the responsiveness to changes in arterial $\mathrm{O}_{2}$ level $(1,5)$. Caffeine also suppresses the respiratory depression typically observed during hypoxia in newborn mammals $(1,5,6)$. This later aspect is in line with data showing that adenosine is released in the brain during hypoxia and its inhibitory effect on neuronal activity helps to reduce neural damages in case of hypoxemia $(4,7)$.

Over the recent years, our knowledge on the mechanisms underlying the high frequency of apneas in preterm neonates

Received December 3, 2009; accepted April 21, 2010.

Correspondence: Aida Bairam, M.D., Ph.D., Centre de Recherche, D0-717, Hôpital Saint-François d'Assise, 10, rue de l'Espinay, Québec, Canada G1L 3L5; e-mail: aida.bairam@crsfa.ulaval.ca

Supported by CIHR operating grant MOP-81101 (to A.B.). V.J. is a research scholar from FRSQ. C.J. is research fellow supported from Téléthon des Étoiles. have expanded, and this may help to better understand the implication of caffeine on these mechanisms. Neonates suffering from recurrent apneas are exposed to repeated hypoxemic episodes (2). The resulting intermittent hypoxia elevates hypoxic responsiveness of peripheral chemoreceptors, which may further contribute to destabilize breathing and increase apnea frequency $(8-10)$. We have shown recently that in rat pups, chronic exposure to intermittent hypoxia during neonatal period (n-IH) enhances both the ventilatory response to a brief hypoxic exposure and apnea frequency (11). Moreover, in our model, n-IH also blunts the ventilatory long-term facilitation (LTF, gradual increase in minute ventilation following several hypoxic episodes), which is sought to reduce the occurrence of repeated apneas in newborn (11) and in adults (12).

To better understand the mechanisms by which caffeine reduces apnea in newborn, we used our model of chronic n-IH (11) to test the specific hypothesis that caffeine reduces apnea frequency by enhancing resting respiratory drive and/or respiratory LTF. We also tested the effects of caffeine on hypoxic response induced by moderate but sustained hypoxia $\left(\mathrm{FiO}_{2}=\right.$ $12 \% ; 20 \mathrm{~min}$ ) to address its impact on the biphasic ventilatory response to hypoxia and on the central integrative processes of hypoxic response or during severe but brief hypoxic episodes $\left(\mathrm{FiO}_{2}=5 \% ; 60 \mathrm{~s}\right)$ to assess particularly the peripheral chemoreceptor response to hypoxia.

\section{MATERIALS AND METHODS}

Ethics. The experimental protocols were approved by the Animal Care Committee at Laval University in accordance with the Canadian Council on Animal Care guidelines.

Mating and $\boldsymbol{n}-\boldsymbol{I H}$. Dam and male Sprague-Dawley rats were obtained from Charles Rivers (St-Constant, Quebec, Canada). The study was performed on 49 Sprague-Dawley rat pups born in our animal care facility from six virgin females and males. Only male pups were studied. Rats were supplied with food and water ad libitum and maintained under standard laboratory conditions $\left(21^{\circ} \mathrm{C}, 12: 12\right.$-h dark-light cycle: lights on at $07: 00 \mathrm{~h}$ and off at 19:00 h). On postnatal d 1 (P1), litters were culled to 12 pups, and males were preferentially selected. Rats were exposed to n-IH between postnatal d $3-12$. This period covers the developmental course of ventilatory control system in rats (13) after the resetting of chemoreceptors, which occurs during the first $2-3 \mathrm{~d}$ of life $(13,14)$. This period also mostly parallels developmental stages of premature infant between 20 and 40 wk postconception (15). Chronic n-IH exposure was performed as previously described (11). Briefly,

Abbreviations: $\mathbf{F i O}_{2}$, inspired oxygen fraction; LTF, long term facilitation; $\mathbf{n}-\mathbf{I H}$, neonatal intermittent hypoxia; $\mathbf{V}_{\mathbf{E}}$, Minute ventilation; $\mathbf{V}_{\mathbf{E}} / \mathbf{V C O}_{\mathbf{2}}$, carbon dioxide convection ratio; $\mathbf{V}_{\mathbf{E}} / \mathbf{V O} \mathbf{O}_{2}$, oxygen convection ratio; $\mathbf{V C O}_{2}$, carbon dioxide production; $\mathbf{V O}_{2}$, oxygen consumption 
female rats with their pups were introduced in the hypoxic room (internal volume $0.05 \mathrm{~m}^{3}$ ) on postnatal $\mathrm{d} 2$ to ensure adaptation to new environment; then, IH exposure began on P3 for 10 consecutive days (P3-P12) using an oxycycler (Biosperix, Redfield, NY). Each cycle consisted in a decrease in oxygen from 21 to $5 \%$ in $100 \mathrm{~s}$, return to $21 \%$ in $140 \mathrm{~s}$, then normoxia for 6 min for a total duration of $10 \mathrm{~min}$, repeated 6 times/h and followed by $1 \mathrm{~h}$ of normoxia, $24 \mathrm{~h} / \mathrm{d}(11)$.

Ventilatory and metabolic recordings. Respiratory and metabolic parameters were recorded at P12 using whole body flow-through plethysmography (IOX; Emka technologies, Paris, France) as regularly used (11). The temperature inside the plethysmograph was fixed at $30^{\circ} \mathrm{C}$ using a temperaturecontrol system (Physitemp, Clifton, NJ). Rectal temperature was measured before and at the end of the experiment using a thermocouple for small rodents (Harvard, Holliston, MA). Respiratory frequency and tidal volume were recorded from the plethysmograph signal. The gas flow through the plethysmograph was set at $100 \mathrm{~mL} / \mathrm{min}$, constantly measured with a mass flowmeter (4140; TSI, Shoreview, MN). Respiratory gases $\left(\mathrm{O}_{2}\right.$ and $\left.\mathrm{CO}_{2}\right)$ were continuously recorded using dedicated gas analyzers (AEI Technologies; Naperville, IL). Tidal volume was corrected depending on barometric pressure, room and body temperature, and humidity (BTPS) (16). Then, minute ventilation $\left(\mathbf{V}_{\mathrm{E}}=\right.$ respiratory frequency $\times$ tidal volume), oxygen consumption $\left[\mathrm{VO}_{2}=\right.$ flow $\times\left(\left(\mathrm{O}_{2}\right.\right.$ in $-\mathrm{O}_{2}$ out $)-\left(\mathrm{O}_{2}\right.$ out $\times\left(\mathrm{CO}_{2}\right.$ out $-\mathrm{CO}_{2}$ in $\left.)\right) /(1-$ $\mathrm{O}_{2}$ out $\left.)\right]$, and $\mathrm{CO}_{2}$ production $\left[\mathrm{VCO} 2=\right.$ flow $\times\left(\mathrm{CO}_{2}\right.$ out $-\mathrm{CO}_{2}$ in $)-$ $\mathrm{CO}_{2}$ out $\times\left(\mathrm{O}_{2}\right.$ in $-\mathrm{O}_{2}$ out $\left.)\right) /\left(1-\mathrm{CO}_{2}\right.$ out $\left.)\right]$ were calculated, corrected to STPD conditions, and used for calculation of oxygen $\left(\mathbf{V}_{\mathrm{E}} / \mathrm{VO}_{2}\right)$ and carbon dioxide $\left(\mathbf{V}_{\mathrm{E}} / \mathrm{VCO}_{2}\right)$ convection ratio (17).

Experimental protocol. Pups were randomly assigned to receive intraperitoneal saline (n-IH + saline, $2 \mu \mathrm{L} / \mathrm{g} ; n=24)$ or caffeine citrate $(\mathrm{n}-\mathrm{IH}+$ caffeine, $20 \mathrm{mg} / \mathrm{kg}, 2 \mu \mathrm{L} / \mathrm{g} ; n=25) 30 \mathrm{~min}$ before starting the experiment. In each litter, there were a roughly equal number of pups receiving saline or caffeine. After body temperature measurement, baseline variables $\left(\mathrm{FiO}_{2}=\right.$ $21 \%$ ) were recorded for $10 \mathrm{~min}$. Then, the pup was exposed to either sustained or brief hypoxia. 1) The sustained hypoxic test was conducted on n-IH + saline pups $(n=13)$ and on $n-\mathrm{IH}+$ caffeine pups $(n=13)$. After normoxic measurements, the inlet gas line was switched to a nitrogen tank to reach $12 \%$ $\mathrm{O}_{2}$ in $\sim 3 \mathrm{~min}$ (maintained for $20 \mathrm{~min}$ ). At the end of the recording, body temperature was immediately measured. 2) The brief intermittent hypoxic test was conducted on $\mathrm{n}-\mathrm{IH}+$ saline pups $(n=11)$ and on $\mathrm{n}-\mathrm{IH}+$ caffeine pups $(n=12)$. After normoxic measurements, the inflowing air was switched to a nitrogen tank allowing a rapid decrease of oxygen from 21 to $5 \%$ in $60 \mathrm{~s}$, return to $21 \%$ in $120 \mathrm{~s}$, followed by 5 min normoxia (11). A total of 10 brief hypoxic episodes were performed, with a peak-to-peak period of $8 \mathrm{~min}$.

Ventilatory measurements during recovery (ventilatory LTF). At the end of the 10 brief hypoxic episodes, ventilation was recorded for $2 \mathrm{~h}$ to assess LTF (11). Body temperature was measured at the end of this period.

Apneas frequency. Two types of apneas were distinguished using standardized criteria (18). Spontaneous apneas were defined as interruption of flow for at least two normal respiratory cycles. A breath with amplitude at least twice the resting tidal volume preceded postsigh apneas. Apnea frequency was analyzed during baseline $(10 \mathrm{~min})$ and the last hour recovery. Because postsigh apneas were rare under normoxic conditions, only spontaneous apneas were calculated. Apnea duration was expressed in seconds.

Assessment of plasma caffeine concentration. Plasma caffeine levels were assessed with an enzyme immunoassay (Emit Caffeine Assay; Syva, Simens, IL) by the St-Justine biochemistry laboratory (Montreal, QC) in rats used for measurements of ventilatory LTF. At the end of the recovery, each rat was anesthetized with a mixture of ketamine $(100 \mu \mathrm{g} / 100 \mathrm{~g})$ and xylazine (15 $\mu \mathrm{g} / 100 \mathrm{~g}$ ), and blood was collected via intracardiac puncture. In rats that received saline, caffeine level was not detectable $(<1 \mathrm{mg} / \mathrm{L} ; n=6)$; whereas in rats that received caffeine citrate $(20 \mathrm{mg} / \mathrm{kg}$, intraperitoneally $n=6)$, the plasma level was $15.4 \pm 2.8 \mathrm{mg} / \mathrm{L}$ (range $8.7-24.1 \mathrm{mg} / \mathrm{L}$ ), which is close to that achieved in babies $(1-3,5)$.

Data collection and statistics. Ventilatory and metabolic variables were obtained on a minute-by-minute basis using the IOX software (version 1.8.9; EMKA technology, Paris, France); they were averaged for the last $5 \mathrm{~min}$ for the baseline and in bouts of $5 \mathrm{~min}$ during the recovery time, i.e., at $0-5$, 25-30, 55-60 and 115-120 min. For the sustained hypoxic response, ventilatory variables were obtained on a minute-by-minute basis for the first 10 min of hypoxia while the last $10 \mathrm{~min}$ were averaged by epochs of 5 min each. For intermittent hypoxic episodes, ventilatory variables were averaged every $10 \mathrm{~s}$ for the first $2 \mathrm{~min}$ ( 1 min hypoxia +1 min re-oxygenation) and the last $10 \mathrm{~s}$ of the 3rd, 5th, and 8th minutes for each cycle. We retained values of the 1st, 5th, and 10th hypoxic episodes to determine differences in response between episodes and treatment. Responses to hypoxia were expressed as percent of baseline in both saline and caffeine groups.

All results were expressed as mean \pm SEM. Data analyses were performed with statview (SAS institute, Inc., Cary, NC). We used the nonparametric
Mann-Whitney $U$ rank sum test to assess differences between groups. For the hypoxic response and during recovery, we used the Wilcoxon signed rank test in each group to assess changes from baseline; the level of significance was adjusted by the Bonferroni correction. Correlations between apnea frequency and ventilation were tested using a spearman nonparametric test on data pooled from both groups because ANCOVA showed no significant effect of treatment on the relationship between minute ventilation and apnea frequency (ANCOVA $p=0.64$ for baseline and $p=0.30$ for recovery). Significance was defined at $p<0.05$.

\section{RESULTS}

Effects of caffeine on baseline ventilation in chronic $\boldsymbol{n}$-IH pups. Body weight, body temperature, baseline ventilatory, and metabolic parameters are shown in Table $1 . \mathrm{V}_{\mathrm{E}}$ was higher in caffeine than in saline pups because of increased respiratory frequency (Table 1). Although $\mathrm{VO}_{2}$ was higher in caffeine than saline pups, $\mathrm{VCO}_{2}$ was similar, whereas $\mathrm{VO}_{2}$ and $\mathrm{V}_{\mathrm{E}} /$ $\mathrm{VCO}_{2}$ were not different between groups (Table 1 ). This likely indicates that ventilation is regulated to match the higher oxygen consumption rate induced by caffeine injection. Because baseline values were different, hypoxic ventilatory responses were normalized to baseline.

\section{Effects of caffeine on hypoxic ventilatory response in chronic n-IH pups}

Sustained hypoxia. Minute ventilation reached its maximal level around the 3rd minute of hypoxic exposure in both saline and caffeine pups (Fig. 1A). Ventilation then decreased gradually to achieve a stable steady state. The frequency response was slightly lower in caffeine than in saline at the end of hypoxic exposure (Fig. $1 B$ ), whereas ventilation and tidal volume responses were similar between groups throughout the exposure (Fig. $1 A$ and $C$ ).

At the end of hypoxic exposure, body temperature was reduced in saline but not in caffeine pups (Fig. 2A). However, there was no difference between groups for $\mathrm{VO}_{2}, \mathrm{VCO}_{2}$, $\mathrm{V}_{\mathrm{E}} / \mathrm{VO}_{2}$, and $\mathrm{V}_{\mathrm{E}} / \mathrm{VCO}_{2}$ (Fig. $2 B$ ).

Brief hypoxic episodes. Figure $3 A$ and $B$ showed schematic representation of brief hypoxic episodes. Respiratory variables increased to similar levels in saline and caffeine pups independently of the hypoxic episodes (Fig. 3C-E). There was no major difference between groups or between episodes at each time point during the hypoxic exposure.

Table 1. Body weight, body temperature, and ventilatory and metabolic variables in 12-d-old rats exposed to chronic neonatal intermittent hypoxia from 3 to 12 postnatal $d$

\begin{tabular}{lccc}
\hline \multicolumn{1}{c}{ Groups } & $\begin{array}{c}\text { Saline } \\
(n=24)\end{array}$ & $\begin{array}{c}\text { Caffeine } \\
(n=25)\end{array}$ & $p$ \\
\hline Body weight $(\mathrm{g})$ & $19.1 \pm 0.8$ & $19.8 \pm 1.0$ & $\mathrm{NS}$ \\
Body temperature $\left({ }^{\circ} \mathrm{C}\right)$ & $34.3 \pm 0.3$ & $34.0 \pm 0.2$ & $\mathrm{NS}$ \\
$\mathrm{V}_{\mathrm{E}}(\mathrm{ml} / \mathrm{min} / 100 \mathrm{~g})$ & $189 \pm 10$ & $247 \pm 15$ & 0.01 \\
Respiratory frequency $(\mathrm{min})$ & $166 \pm 4$ & $184 \pm 4$ & 0.02 \\
Tidal volume $(\mathrm{ml} / 100 \mathrm{~g})$ & $1.1 \pm 0.1$ & $1.3 \pm 0.1$ & $\mathrm{NS}$ \\
$\mathrm{VO}_{2}(\mathrm{ml} / \mathrm{min} / 100 \mathrm{~g})$ & $5.3 \pm 0.3$ & $6.2 \pm 0.3$ & 0.03 \\
$\mathrm{VCO}_{2}(\mathrm{ml} / \mathrm{min} / 100 \mathrm{~g})$ & $3.5 \pm 0.2$ & $4.0 \pm 0.3$ & $\mathrm{NS}$ \\
$\mathrm{V}_{\mathrm{E}} / \mathrm{VO}_{2}$ & $37 \pm 3$ & $39 \pm 2$ & $\mathrm{NS}$ \\
$\mathrm{V}_{\mathrm{E}} / \mathrm{VCO}_{2}$ & $56 \pm 5$ & $62 \pm 4$ & $\mathrm{NS}$ \\
\hline
\end{tabular}

Metabolic data were measured on $13 \mathrm{n}$-IH rats of each saline and caffeine. Data are given as mean \pm SEM.

$\mathrm{V}_{\mathrm{E}}$, minute ventilation; $\mathrm{VO}_{2}$, oxygen consumption; $\mathrm{VCO}_{2}$, carbon dioxide production; $\mathrm{V}_{\mathrm{E}} / \mathrm{VO}_{2}$, oxygen convection ratio; $\mathrm{V}_{\mathrm{E}} / \mathrm{VCO}_{2}$, carbon dioxide convection ratio. 

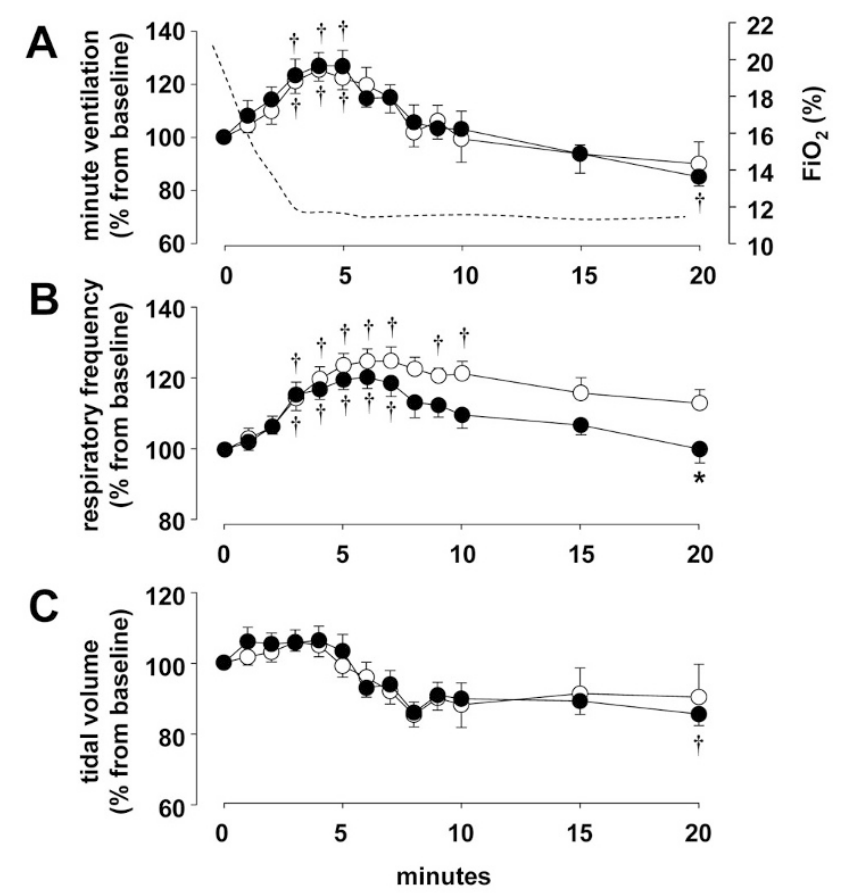

Figure 1. Ventilatory response to $20 \mathrm{~min}$ hypoxic exposure. Data are percentage changes from baseline for minute ventilation $(A)$, respiratory frequency $(B)$, and tidal volume $(C)$ in 12-d-old rats previously exposed to intermittent hypoxia from postnatal d 3-12. $\bigcirc$ : saline group, $n=13$; caffeine group, $n=13$; dashed line in $A$ represents the temporal decrease in $\mathrm{FiO}_{2}$. Data are mean \pm SEM $* p<0.03$ vs saline; $\dagger p<0.05$ vs baseline.

\section{Effects of caffeine on ventilation during recovery period} (ventilatory LTF) in chronic n-IH pups. In pups that received caffeine, minute ventilation increased gradually during recovery, whereas it remained stable in saline pups (Fig. 4A). This was mostly because of a gradual increase of tidal volume (Fig. $4 C$ ), whereas respiratory frequency was slightly lower in caffeine than in saline pups (Fig. $4 B$ ). At the end of the recovery period, body temperature (Fig. $5 A$ ), $\mathrm{VO}_{2}$ and $\mathrm{VCO}_{2}$ (Fig. $5 B$ ) were similar between groups. However, $\mathrm{V}_{\mathrm{E}} / \mathrm{VO}_{2}$ and $\mathrm{V}_{\mathrm{E}} / \mathrm{VCO}_{2}$ were higher in caffeine than in saline pups (Fig. $5 B$ ).

Effects of caffeine on apnea frequency and duration in chronic n-IH pups. During baseline recordings, apnea frequency was significantly lower in caffeine than in saline pups $(p<0.02$; Fig. 6A). Apnea frequency was negatively correlated with minute ventilation $\left(p<0.01, R^{2}=0.34\right.$; Fig. $\left.6 B\right)$.
During the recovery period, apnea frequency was also lower in caffeine than in saline rats $(p<0.02$; Fig. 6C). Apnea frequency was also negatively correlated with the percentage changes of minute ventilation from baseline $\left(p<0.01, R^{2}=\right.$ 0.52; Fig. $6 D$ ), which was related to the establishment of ventilatory LTF by hypoxic episodes. Finally, apnea duration was not affected by caffeine in all conditions (Fig. $6 A$ and $C$ ).

\section{DISCUSSION}

This study shows that caffeine failed to increase the hypoxic ventilatory response but enhanced baseline metabolic rate, basal ventilation, and ventilatory LTF in 12-d-old rat that have previously been exposed to intermittent hypoxia from postnatal d 3-12. The decrease in apnea frequency was positively correlated with the increase of normoxic minute ventilation induced by caffeine. During the recovery period, apnea frequency was positively correlated to the changes in minute ventilation reflecting the establishment of ventilatory LTF induced by hypoxic episodes. This suggests that caffeine reduces apnea frequency by augmenting respiratory drive (independently on hypoxic chemoreflex) and by enhancing ventilatory LTF.

Caffeine and hypoxic ventilatory response. The current data failed to show any effects of caffeine on the ventilatory response to hypoxia under sustained or brief exposures. This result contrast with several studies obtained in different animal species $(19,20)$ and in preterm babies $(1,5)$ in which caffeine administration increases the hypoxic ventilatory response. The release of adenosine during hypoxia contributes to reduce ventilation during the second phase of the hypoxic exposure, and it has been shown that this effect is antagonized by caffeine or xanthine derivatives in newborn rats, rabbits, piglets, or lamb (7,19-22). The difference between our data and the well-known ventilatory effects of xanthines may be related to the experimental approaches. In particular, we used rats that were chronically exposed to intermittent hypoxia, which may have impaired the neurotransmitters pathways (either at peripheral chemoreceptors or in the central nervous system) involved in respiratory control including the adenosinergic transmission system (6). Indeed, n-IH exposure for $10 \mathrm{~d}$ enhances the hypoxic ventilatory response (11); in this context, caffeine may not be able to further improve this response. Another aspect might be related to the age of the animals (12 d) and length of n-IH exposure, both of which may affect the extent to which caffeine can improve hypoxic ventilatory response.
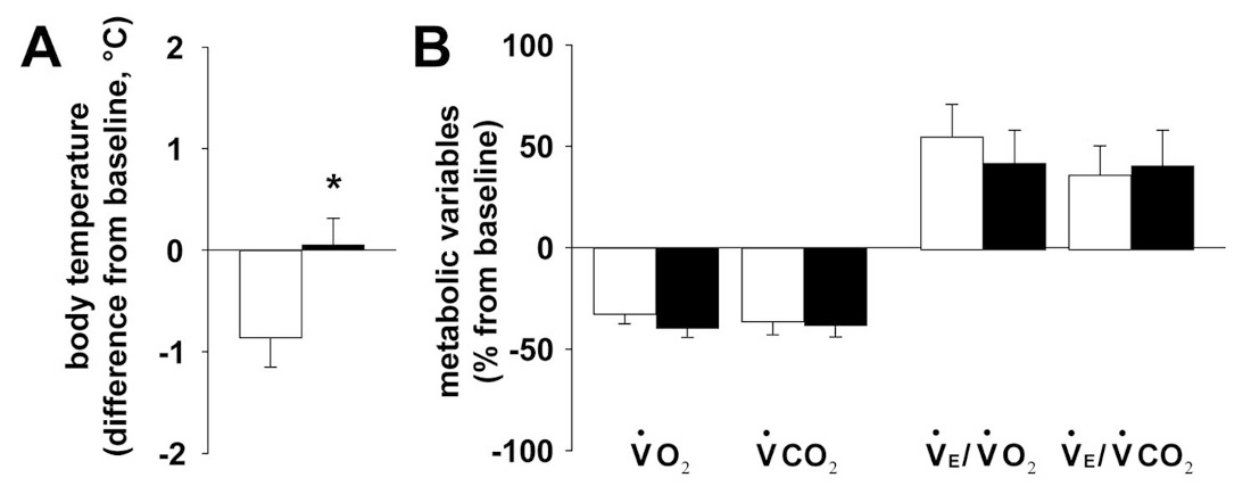

Figure 2. Body temperature $(A)$ and metabolic variables $(B)$ response to $20 \mathrm{~min}$ hypoxic exposure. Data are absolute difference $(A)$ or \% changes $(B) v s$. baseline in 12-d-old rats previously exposed to intermittent hypoxia from postnatal d 3-12. $\square$ : saline group, $n=13$; $\mathbf{\square}$ : caffeine group, $n=13$. Data are mean \pm SEM $* p<0.03$ vs saline. 
A

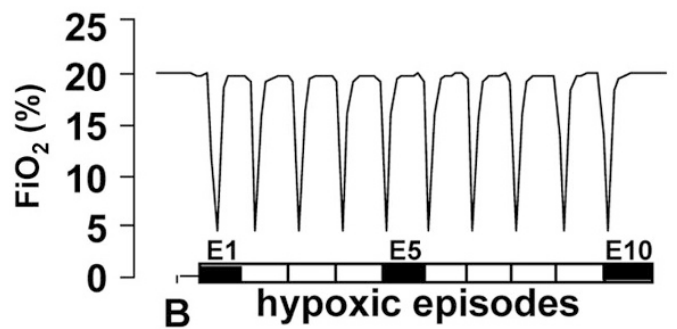

B

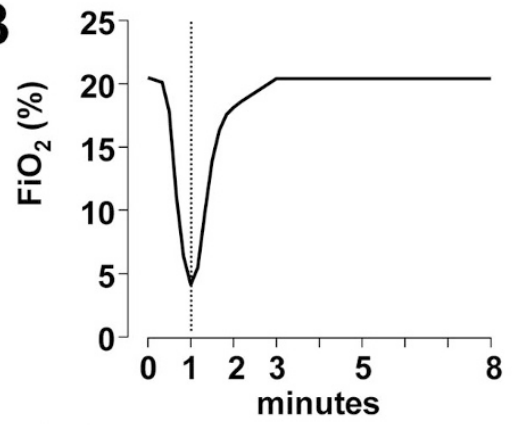

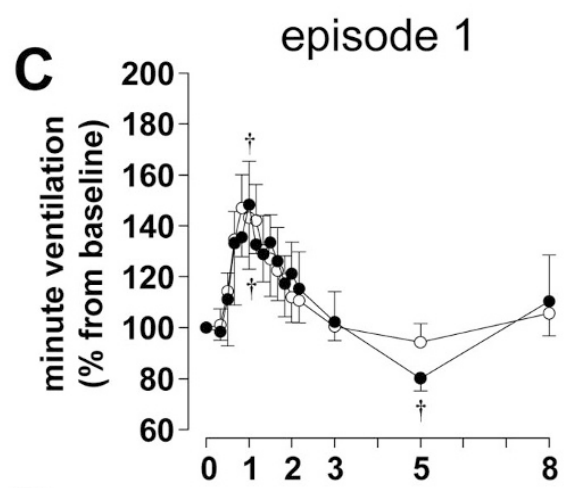

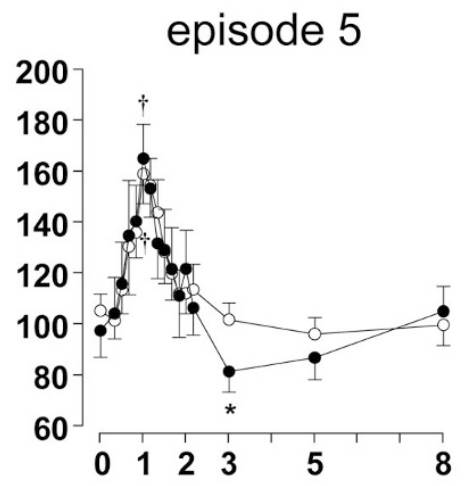

episode 10
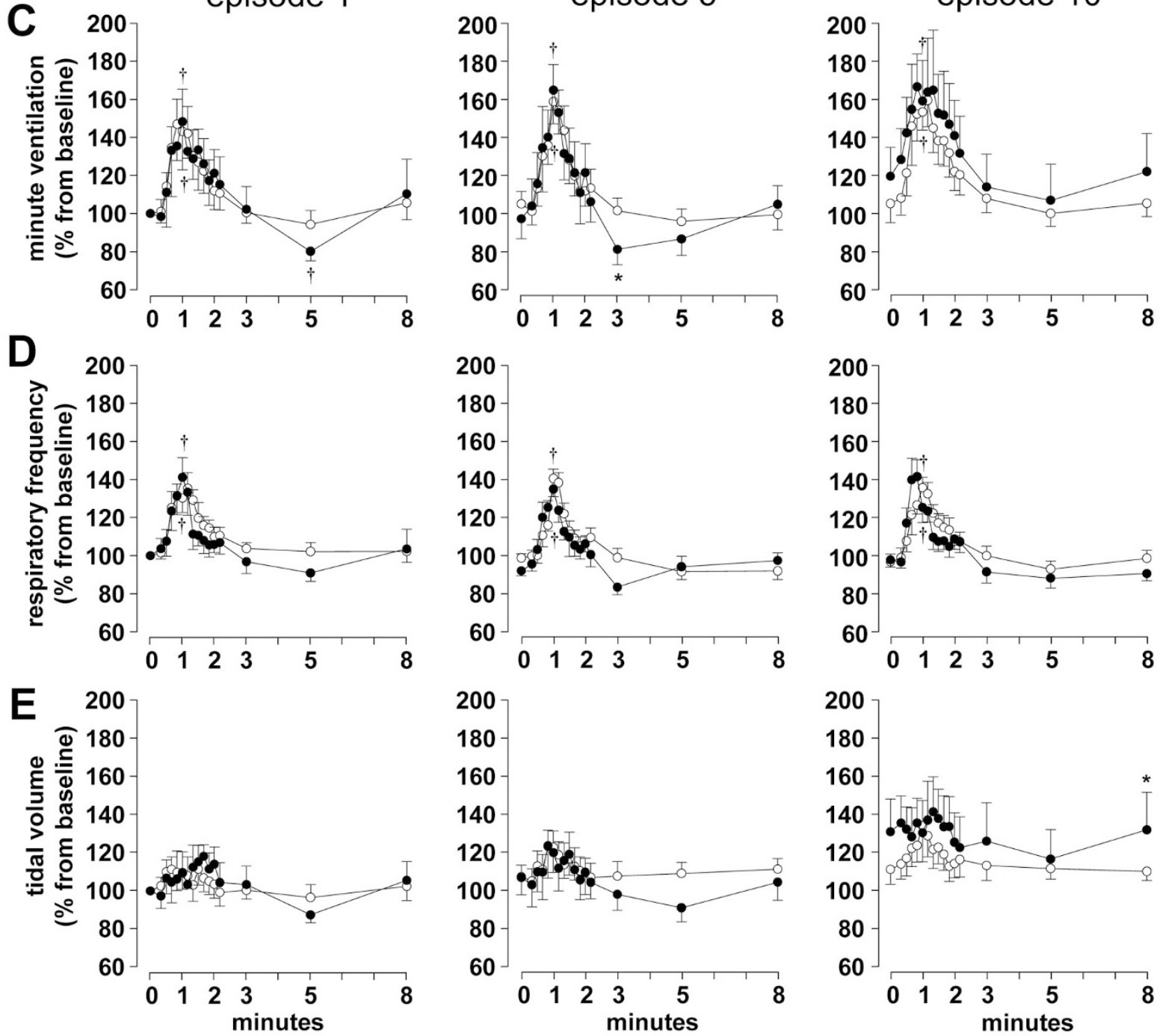

Figure 3. Ventilatory response to brief hypoxic exposures. Representation of the hypoxic episodes $(A)$; temporal decrease of oxygen during one hypoxic episode $(B)$; and, \% changes from baseline of minute ventilation $(C)$, respiratory frequency $(D)$ and tidal volume $(E)$ for the 1st, 5th, and 10th hypoxic episodes. These measures were performed in 12-d-old rats previously exposed to intermittent hypoxia from postnatal d 3-12. $\bigcirc$ : saline group, $n=11$; $\mathbf{0}$ : caffeine group, $n=$ 12. Data are mean \pm SEM $* p<0.04 v s$ saline; $\dagger p<0.05 v s$ baseline.

It might also be worth mentioning that the effects of caffeine on carotid body function are still controversial. In developing kitten, in vivo recording of afferent fibers of the carotid sinus nerve showed that caffeine (either at low therapeutic or high toxic doses) does not affect the carotid body chemosensory response to hypoxia (23). However, in vitro, a very high concentration $(10 \mathrm{mM})$ of caffeine was needed to depress the carotid sinus nerve chemosensory activity in adult rats (24). Finally, it should also be mentioned that we used a single dose of caffeine, which contrasts with its chronic clinical use to treat apnea in newborn $(1,2,5)$.

Caffeine and apnea. The assumption that caffeine reduces apnea frequency by enhancing hypoxic ventilatory response is not supported by our data. However, our results are in line 

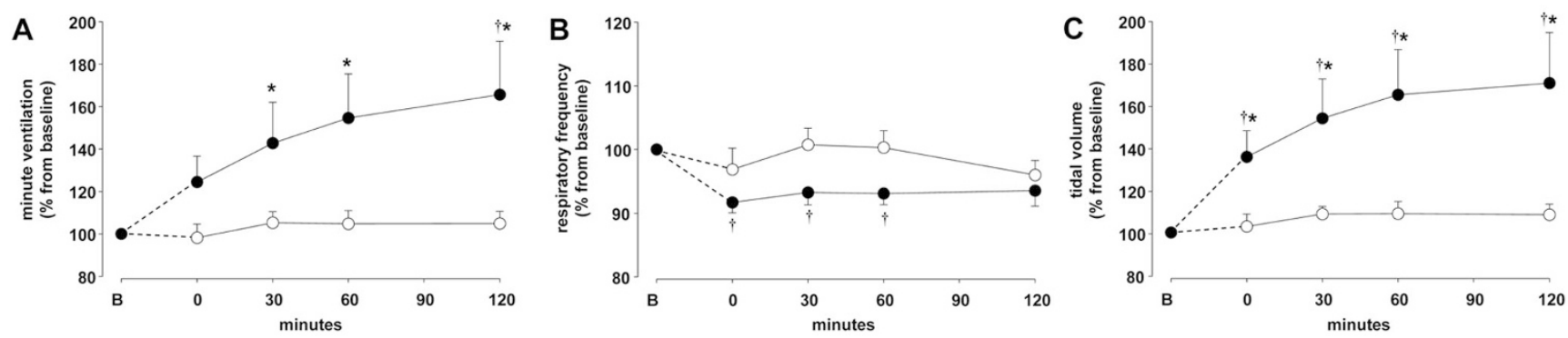

Figure 4. Ventilatory LTF during recovery. Percentage changes from baseline for minute ventilation $(A)$, respiratory frequency $(B)$, and tidal volume $(C)$ during recovery measured in 12-d-old rats previously exposed to intermittent hypoxia from postnatal d 3-12. $\bigcirc$ : saline group, $n=11 ; \boldsymbol{\bullet}$ : caffeine group, $n=12$. Data are mean \pm SEM $* p<0.05$ vs saline; $\dagger p<0.05$ vs baseline.
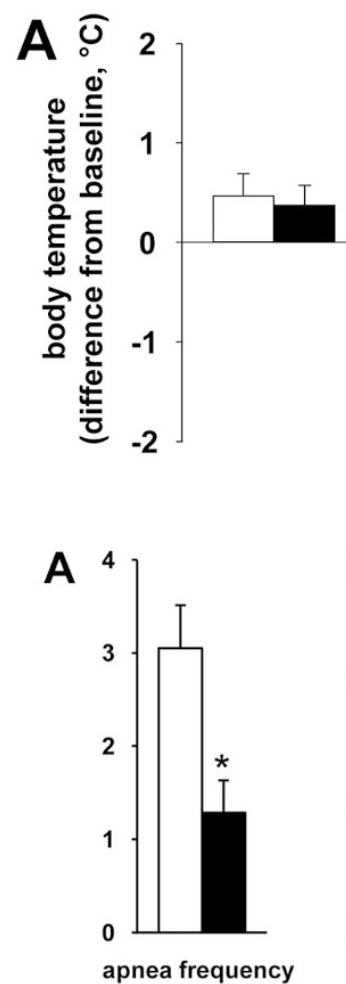
(/10 min)

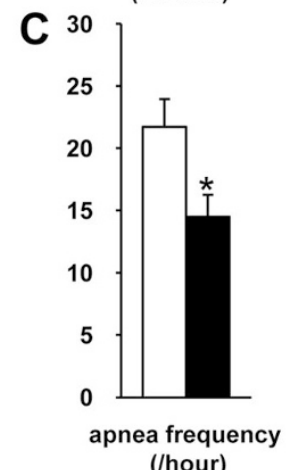

(/hour)
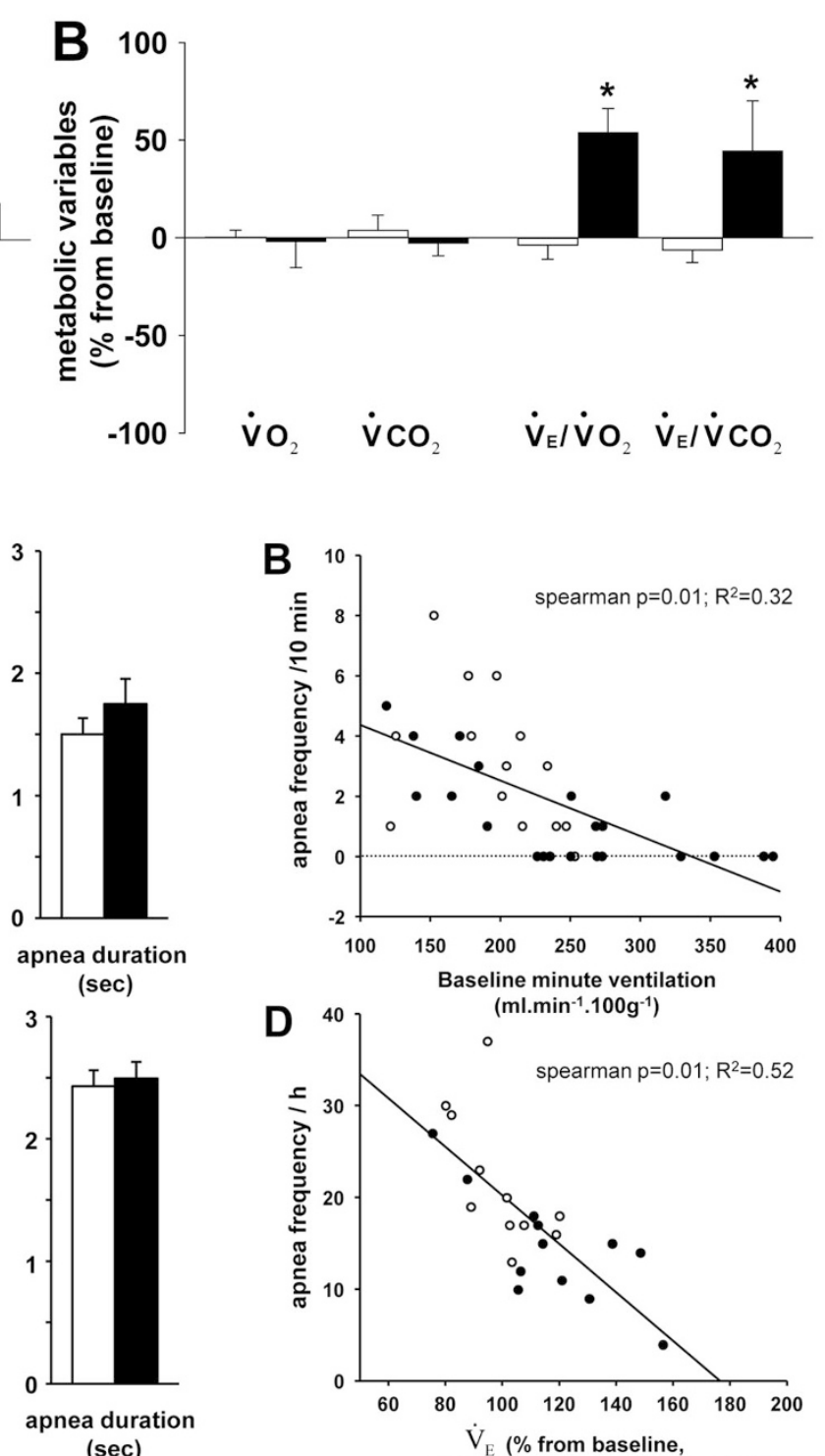

(sec)
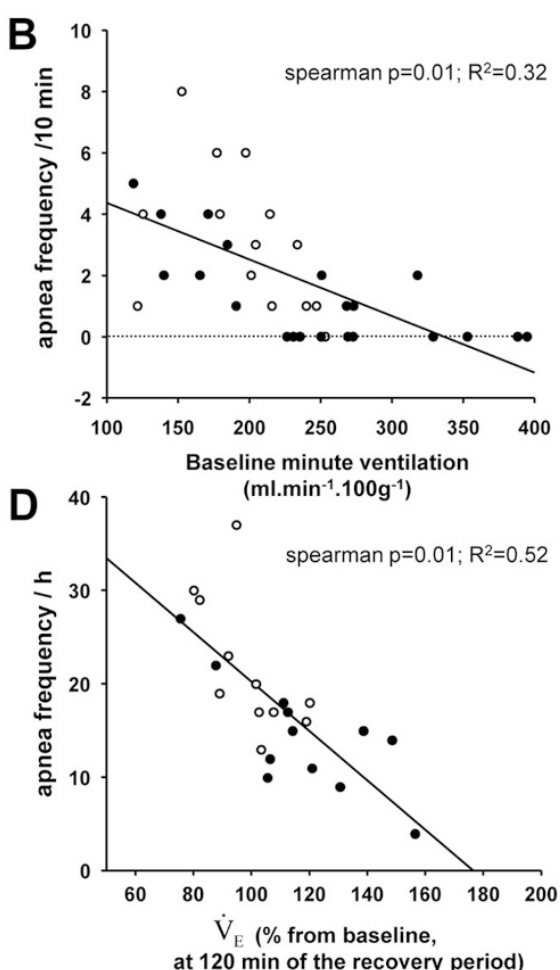

Figure 5. Body temperature $(A)$ and metabolic variables $(B)$ during recovery. Data are absolute difference $(A)$ or $\%$ changes $(B)$ vs. baseline in 12-d-old rats previously exposed to intermittent hypoxia from postnatal d 3-12. $\square$ : saline group, $n=11$; $\mathbf{\square}$ : caffeine group, $n=12$. Data are mean \pm SEM $* p<0.03$ vs saline.
Figure 6. Apnea frequency and durationcorrelation between apnea frequency and minute ventilation at baseline ( $A$ and $B$ ); and during the recovery period $(C$ and $D$ ) in 12-d-old rats previously exposed to intermittent hypoxia from postnatal d 3-12. Data are mean \pm SEM * $p<$ 0.02 vs saline. $\square$ and $\bigcirc$ : saline group; $\square$ and $\bullet$ caffeine group. with the evidence that caffeine efficacy on apnea and periodic breathing relies on stimulation of central respiratory drive $(1,5,6,25)$. In $n-I H$ rat pups, caffeine enhanced basal metabolic rate and ventilation mainly through an increase in respiratory frequency under resting condition. Most notably, caffeine allowed the expression of ventilatory LTF during recovery after acute hypoxic episodes. In addition, there was a clear correlation between higher level of ventilation and lower apnea frequency (not duration) in both cases. These results support the hypothesis that suppression of respiratory LTF as observed in n-IH rat pups (11) contributes to enhance apnea frequency and suggests that caffeine reduces apneas, at least 
partly, by allowing the expression of ventilatory LTF. The lack of effects of caffeine on hypoxic ventilatory response may explain its lack of effect on apnea duration, because apneas are terminated by the activation of peripheral and central chemoreceptors as critical blood gas values are reached (26). Finally, other mechanisms might have been implicated such as an effect of caffeine on lung mechanic (27). It is worth to note that babies receiving caffeine show better success for weaning from mechanical ventilation and shorter duration for continuous positive airway pressure support (28).

Caffeine and adenosinergic system. Caffeine as antagonist of adenosine $\mathrm{A}_{1}$ and $\mathrm{A}_{2 \mathrm{~A}}$ receptors stimulates respiration $(4,7,19-22)$. The observation that caffeine enhanced baseline ventilation and ventilatory LTF supports its central action in $\mathrm{n}-\mathrm{IH}$ rats. Adenosine is released in response to hypoxia and interacts with many neurotransmitter systems that play significant role in the respiratory control maturation such as GABA, glutamate, serotonin, and adrenergic system. The available data show that these interactions are highly sensitive to adverse conditions during neonatal period such as chronic exposure to hypoxia or hyperoxia $(4,6)$. For instance, prenatal hypoxic exposure alters the carotid body and brainstem tyrosine hydroxylase content and ventilation in young rats (3-21 d), but these effects do not persist at 2 mo of age (29). The underlying mechanisms of ventilatory control disruption because of chronic neonatal intermittent hypoxia exposure are not fully understood. Interestingly, a recent study in anesthetized adult rats showed that inhibition of spinal cord $\mathrm{A}_{2 \mathrm{~A}}$ receptors (but not $A_{1}$ ) enhances phrenic LTF induced by intermittent hypoxia (30).

Experimental limitations. The use of whole-body plethysmography to estimate ventilation in unrestrained and nonanesthetized newborn is subject to experimental errors related to the accuracy in the assessments of tidal volume. This point has been previously discussed in details (11). Despite the limitations inherent to tidal volume measurements, all experimental groups were studied under similar conditions. Another limitation in our experimental design is that we did not take into consideration the sleep-wake state during recordings and we have no data whether n-IH per se affects sleep organization. Sleep/wake cycles are very brief during the first postnatal week in newborn rats (31) and contradictory effects of caffeine are reported in premature infants with either no effects (32) or sleep deprivation (33). Although caffeine may have reduced sleep time in rat pups, it is unlikely that this would interfere with ventilatory LTF expression.

\section{CONCLUSION}

Our results show that caffeine has no effect on hypoxic ventilatory reflexes in newborn rats raised under chronic neonatal intermittent hypoxia. However, they support the hypothesis that caffeine reduces apnea frequency through central stimulation of respiration and by enhancing the expression of ventilatory LTF. Caffeine treatment is frequently prolonged for several weeks or months in human preterm neo- nates (1). It is worth mentioning that both prenatal nicotine (34) and alcohol exposure (35) inhibit LTF establishment in rat pups and that caffeine might also be helpful to establish LTF in these cases.

Acknowledgments. We thank Dr R. Kinkead for his valuable comments; Mme Mélanie Pelletier and Sylvie Viger for animal care; and Mr Merlin M. Njoya (MSc in biostatistics, CHUQ Research Center) for statistical design.

\section{REFERENCES}

1. Aranda JV, Turmen T 1979 Methylxanthines in apnea of prematurity. Clin Perinatol 6:87-108

2. Henderson-Smart DJ, Steer PA 2010 Caffeine versus theophylline for apnea in preterm infants. Cochrane Database Syst Rev CD000273

3. Bairam A, Boutroy MJ, Badonnel Y, Vert P 1987 Theophylline versus caffeine: comparative effects in treatment of idiopathic apnea in the preterm infant. J Pediatr 110:636-639

4. Fredholm BB, Battig K, Holmen J, Nehlig A, Zvartau EE 1999 Actions of caffeine in the brain with special reference to factors that contribute to its widespread use. Pharmacol Rev 51:83-133

5. Marchal F, Bairam A, Vert P 1987 Neonatal apnea and apneic syndromes. Clin Perinatol 14:509-529

6. Darnall RA, Ariagno RL, Kinney HC 2006 The late preterm infant and the control of breathing, sleep, and brainstem development: a review. Clin Perinatol 33:883-914

7. Herlenius E, Lagercrantz H, Yamamoto Y 1997 Adenosine modulates inspiratory neurons and the respiratory pattern in the brainstem of neonatal rats. Pediatr Res 42:46-53

8. Cardot V, Chardon K, Tourneux P, Micallef S, Stephan E, Leke A, Bach V, Libert JP, Telliez F 2007 Ventilatory response to a hyperoxic test is related to the frequency of short apneic episodes in late preterm neonates. Pediatr Res 62:591-596

9. Al-Matary A, Kutbi I, Qurashi M, Khalil M, Alvaro R, Kwiatkowski K, Cates D, Rigatto H 2004 Increased peripheral chemoreceptor activity may be critical in destabilizing breathing in neonates. Semin Perinatol 28:264-272

10. Nock ML, Difiore JM, Arko MK, Martin RJ 2004 Relationship of the ventilatory response to hypoxia with neonatal apnea in preterm infants. J Pediatr 144:291-295

11. Julien C, Bairam A, Joseph V 2008 Chronic intermittent hypoxia reduces ventilatory long-term facilitation and enhances apnea frequency in newborn rats. Am J Physiol Regul Integr Comp Physiol 294:R1356-R1366

12. Mahamed S, Mitchell GS 2007 Is there a link between intermittent hypoxia-induced respiratory plasticity and obstructive sleep apnoea? Exp Physiol 92:27-37

13. Bissonnette JM 2000 Mechanisms regulating hypoxic respiratory depression during fetal and postnatal life. Am J Physiol Regul Integr Comp Physiol 278:R1391-R1400

14. Eden GJ, Hanson MA 1987 Maturation of the respiratory response to acute hypoxia in the newborn rat. J Physiol 392:1-9

15. Clancy B, Darlington RB, Finlay BL 2001 Translating developmental time across mammalian species. Neuroscience 105:7-17

16. Bartlett D Jr, Tenney SM 1970 Control of breathing in experimental anemia. Respir Physiol 10:384-395

17. Mortola JP, Dotta A 1992 Effects of hypoxia and ambient temperature on gaseous metabolism of newborn rats. Am J Physiol 263:R267-R272

18. Mendelson WB, Martin JV, Perlis M, Giesen H, Wagner R, Rapoport SI 1988 Periodic cessation of respiratory effort during sleep in adult rats. Physiol Behav 43:229-234

19. Runold M, Lagercrantz H, Prabhakar NR, Fredholm BB 1989 Role of adenosine in hypoxic ventilatory depression. J Appl Physiol 67:541-546

20. Darnall RA, Bruce RD 1987 Effects of adenosine and xanthine derivatives on breathing during acute hypoxia in the anesthetized newborn piglet. Pediatr Pulmonol 3:110-116

21. Lopes JM, Davis GM, Mullahoo K, Aranda JV 1994 Role of adenosine in the hypoxic ventilatory response of the newborn piglet. Pediatr Pulmonol 17:50-55

22. Koos BJ, Kawasaki Y, Kim YH, Bohorquez F 2005 Adenosine A2A-receptor blockade abolishes the roll-off respiratory response to hypoxia in awake lambs. Am J Physiol Regul Integr Comp Physiol 288:R1185-R1194

23. Bairam A, De Grandpre P, Dauphin C, Marchal F 1997 Effects of caffeine on carotid sinus nerve chemosensory discharge in kittens and cats. J Appl Physiol 82:413-418

24. Conde SV, Obeso A, Vicario I, Rigual R, Rocher A, Gonzalez C 2006 Caffeine inhibition of rat carotid body chemoreceptors is mediated by $\mathrm{A} 2 \mathrm{~A}$ and $\mathrm{A} 2 \mathrm{~B}$ adenosine receptors. J Neurochem 98:616-628

25. Anwar M, Mondestin H, Mojica N, Novo R, Graff M, Hiatt M, Hegyi T 1986 Effect of caffeine on pneumogram and apnoea of infancy. Arch Dis Child 61:891-895

26. Delacourt C, Canet E, Bureau MA 1996 Predominant role of peripheral chemoreceptors in the termination of apnea in maturing newborn lambs. J Appl Physiol 80:892-898 
27. Laubscher B, Greenough A, Dimitriou G 1998 Comparative effects of theophylline and caffeine on respiratory function of prematurely born infants. Early Hum Dev 50:185-192

28. Davis PG, Schmidt B, Roberts RS, Doyle LW, Asztalos E, Haslam R, Sinha S, Tin W 2010 Caffeine for Apnea of Prematurity trial: benefits may vary in subgroups. J Pediatr 156:382-387

29. Peyronnet J, Roux JC, Mamet J, Perrin D, Lachuer J, Pequignot JM, Dalmaz Y 2007 Developmental plasticity of the carotid chemoafferent pathway in rats that are hypoxic during the prenatal period. Eur J Neurosci 26:2865-2872

30. Hoffman MS, Golder FJ, Mahamed S, Mitchell GS 2010 Spinal adenosine A2(A) receptor inhibition enhances phrenic long term facilitation following acute intermittent hypoxia. J Physiol 588:255-266
31. Blumberg MS, Seelke AM, Lowen SB, Karlsson KA 2005 Dynamics of sleep-wake cyclicity in developing rats. Proc Natl Acad Sci USA 102:14860-14864

32. Curzi-Dascalova L, Aujard Y, Gaultier C, Rajguru M 2002 Sleep organization is unaffected by caffeine in premature infants. J Pediatr 140:766-771

33. Hayes MJ, Akilesh MR, Fukumizu M, Gilles AA, Sallinen BA, Troese M, Paul JA 2007 Apneic preterms and methylxanthines: arousal deficits, sleep fragmentation and suppressed spontaneous movements. J Perinatol 27:782-789

34. Fuller DD, Dougherty BJ, Sandhu MS, Doperalski NJ, Reynolds CR, Hayward LF 2009 Prenatal nicotine exposure alters respiratory long-term facilitation in neonatal rats. Respir Physiol Neurobiol 169:333-337

35. Kervern M, Dubois C, Naassila M, Daoust M, Pierrefiche O 2009 Perinatal alcoho exposure in rat induces long-term depression of respiration after episodic hypoxia. Am J Respir Crit Care Med 179:608-614 